\title{
Performance analysis of a cascade high temperature heat pump using R245fa and BY-
} 3 as working fluid

Ma, Xuelian; Zhang, Yufeng; Fang, Lei; Yu, Xiaohui; Li, Xiaoqiong; Sheng, Ying; Zhang, Yan

Published in:

Applied Thermal Engineering

Link to article, DOI:

10.1016/j.applthermaleng.2018.05.052

Publication date:

2018

Document Version

Peer reviewed version

Link back to DTU Orbit

Citation (APA):

Ma, X., Zhang, Y., Fang, L., Yu, X., Li, X., Sheng, Y., \& Zhang, Y. (2018). Performance analysis of a cascade high temperature heat pump using R245fa and BY-3 as working fluid. Applied Thermal Engineering, 140, 466475. https://doi.org/10.1016/j.applthermaleng.2018.05.052

\section{General rights}

Copyright and moral rights for the publications made accessible in the public portal are retained by the authors and/or other copyright owners and it is a condition of accessing publications that users recognise and abide by the legal requirements associated with these rights.

- Users may download and print one copy of any publication from the public portal for the purpose of private study or research.

- You may not further distribute the material or use it for any profit-making activity or commercial gain

- You may freely distribute the URL identifying the publication in the public portal 
Performance analysis of a cascade high temperature heat pump using R245fa and

$$
\text { BY-3 as working fluid }
$$

Xuelian $\mathrm{Ma}^{\mathrm{a}}$, Yufeng Zhang ${ }^{\mathrm{a}}$, Lei Fang ${ }^{\mathrm{b}}$,

Xiaohui Yu ${ }^{\text {a }}$, Xiaoqiong $\mathrm{Li}^{\mathrm{a}}$, Ying Sheng ${ }^{\mathrm{a}, *}$, Yan Zhang ${ }^{\mathrm{c}}$,

${ }^{a}$ School of Environmental Science and Engineering, Tianjin University, Tianjin, 300072, PR China

${ }^{\mathrm{b}}$ International Centre for Indoor Environment and Energy, Department of Civil Engineering, Technical University of Denmark, Lyngby 2800, Denmark

c School of Architecture, Tianjin University, Tianjin, 300072, PR China.

ABSTRACT: A high temperature cascade heat pump (HTCHP) using a near-zeotropic mixture named BY-3 as the working fluid in the low-stage refrigerant cycle and R245fa as working fluid in the high-stage refrigerant cycle was proposed in this study. Several experiments were carried out to investigate the performance of the HTCHP at the evaporating temperature from $40^{\circ} \mathrm{C}$ to $60^{\circ} \mathrm{C}$ and the water outlet temperature on the condensing unit of the high-stage cycle can reach $142^{\circ} \mathrm{C}$ with the coefficient of performance (COP) of 1.72. The results showed that BY-3 was feasible to be used in the low-stage cycle. A numerical model of the HTCHP was proposed and validated in this study to evaluate its performance. The comparison between the experimental results and the simulated results showed that the HTCHP system using BY-3 and R245fa can product hot water at $142^{\circ} \mathrm{C}$ with good performance and the

\footnotetext{
* Corresponding author: Ying Sheng

E-mail: ysheng@tju.edu.cn
}

Address: No. 135 Yaguan Road, Jinnan District, Tianjin, China. 
22 Keywords: High-temperature Cascade Heat Pump; Modeling Analysis;

23 Experimental Verification; Performance Evaluation

\begin{tabular}{|c|c|}
\hline \multicolumn{2}{|l|}{ Nomenclature } \\
\hline COP & Coefficient of performance \\
\hline EEV & Electronic expansion valve \\
\hline HX & Heat exchanger \\
\hline $\mathrm{Cp}$ & Specific heat $(\mathrm{kJ} / \mathrm{kg} \cdot \mathrm{K})$ \\
\hline $\mathrm{m}$ & Mass flow rate(kg/h) \\
\hline $\mathrm{P}$ & Power consumption $(\mathrm{kW})$ \\
\hline $\mathrm{h}$ & Enthalpy(kJ/kg) \\
\hline $\mathrm{T}$ & Temperature $\left({ }^{\circ} \mathrm{C}\right)$ \\
\hline Q & Capacity(kW) \\
\hline W & Power input(kW) \\
\hline НTCHP & $\begin{array}{l}\text { High temperature cascade heat } \\
\text { pump }\end{array}$ \\
\hline $\mathrm{P}_{\mathrm{c}}$ & critical pressure(bar) \\
\hline$P_{\text {theo }}$ & Theoretical power(kW) \\
\hline $\mathrm{P}_{\text {in }}$ & Input power $(\mathrm{kW})$ \\
\hline GWP & Global Warming Potential \\
\hline ODP & Ozone Depleting Potential \\
\hline $\mathrm{r}$ & Latent heat $(\mathrm{kW} / \mathrm{kg})$ \\
\hline$\varnothing$ & EEV opening degree \\
\hline \multicolumn{2}{|l|}{ Subscripts } \\
\hline W & water \\
\hline $\mathrm{v}$ & vapor \\
\hline 1 & liquid \\
\hline $\mathrm{L}$ & Low -stage refrigerant cycle \\
\hline $\mathrm{H}$ & High-stage refrigerant cycle \\
\hline cond & condenser \\
\hline evap & evaporator \\
\hline ref & refrigerant \\
\hline $\mathrm{t}$ & total \\
\hline out & outlet \\
\hline in & inlet \\
\hline \multicolumn{2}{|l|}{ Greek symbols } \\
\hline$\rho$ & density $\left(\mathrm{kg} / \mathrm{m}^{3}\right)$ \\
\hline & acentric factor \\
\hline$\eta_{\mathrm{s}}$ & volumetric efficiency \\
\hline
\end{tabular}




\begin{tabular}{|ll|}
$\eta_{\mathrm{m}}$ & friction efficiency \\
$\eta_{\mathrm{e}}$ & motor efficiency \\
$1,2,3,4,5,6,7,8,9,10$ & state point \\
\hline
\end{tabular}

\section{Introduction}

Environmental concerns such as global warming, ozone depletion, global climate change and air population have become worldwide issues in the past several decades mainly due to anthropogenic activities such as vehicle emission, pollutions from power plants, steel mills, and many other industrial sectors ${ }^{[1][2]}$. The use of substantial fossil fuels contributes this the most, especially the fuel consumption on the industrial aspect. It was reported that the energy was accounted for more than $70 \%$ of China's total energy consumption in 2010. In the U.S., the industrial sector accounted for about one third of the total energy consumed and it was estimated that 20 to $50 \%$ of industrial energy input was lost as waste heat in different forms ${ }^{[3]}$. Consequently, new technologies that can improve energy efficiency and recover waste heat losses provide an attractive challenge for an emission-free and less-costly energy resource.

The cascade refrigeration system composed of two independent refrigerant cycles was first introduced in1930s to overcome the disadvantage such as high pressure ratio and low COP of single-stage refrigeration in low-temperature refrigeration systems in the range from $-30^{\circ} \mathrm{C}$ to $-100^{\circ} \mathrm{C}^{[4][5]}$. Jung et al. drew the conclusion that the cascade heat pump was much more competitive than single-stage heat pump by studying a cascade multifunctional heat pump using R410A and R134a as working fluids experimentally ${ }^{[6]}$.

Many researches have been done to investigate the performance of the cascade heat pump systems. Wang et al. performed series of experiments to analyze the 
impact of different operation parameters on the performance of cascade refrigeration and concluded that the $\mathrm{NH}_{3} / \mathrm{CO}_{2}$ cascade was competitive in low temperature applications ${ }^{[7]}$. Alberto et al. designed and built a cascade refrigeration system with $\mathrm{NH}_{3}$ and $\mathrm{CO}_{2}$ to study the system performance and the results accords with the trends obtained from the theoretical researches published in technical literature ${ }^{[8]}$. Qu et al. presented a control method of air source heat pump and verified it experimentally and the experimental results showed that the control strategy could realize the control of evaporating temperature and intermediate pressure with high accuracy and sensitivity to adjust the system load variation ${ }^{[9]}$. Park ${ }^{[10]}$ set up a mathematical model of $\mathrm{R} 134 \mathrm{a} / \mathrm{R} 410 \mathrm{~A}$ cascade heat pump to predict the optimal intermediate temperature to make sure that the system can run with higher COP based on thermodynamic laws and thermodynamic properties of refrigerants. $\mathrm{Kim}^{[11]}$ verified the optimal intermediate temperature by experimental investigation conducted on an air to water heat pump, and the numerical model can predict the experimental results with high accuracy. Hansaem ${ }^{[12]}$ et.al studied the performance of a cascade heat pump system by quasi-steady state analysis and Cho ${ }^{[13]}$ et al. investigated a two-stage $\mathrm{CO}_{2}$ system in cooling mode operation.

As a main contributor to productivity and employment in China, the petroleum refining industry consumed approximately $15 \%{ }^{[14]}$ of industrial fuel oil and $10 \%$ of industrial coal. During recent years, capacity expansion activities had been carried out for lots of petroleum refining companies, but during the design and construction, the heating capacity between the new and old facilities was not integrated well. Accordingly, lots of low temperature waste heating was produced. Take a a 10 million-ton refinery, the low temperature waste heat was about $1000 \times 10^{4} \sim 12000 \times$ $10^{4} \mathrm{kcal} / \mathrm{h}$, the current comprehensive utilization efficiency was only $30 \%$ to $50 \%$, 
through comprehensive optimization of low temperature heat, the comprehensive utilization rate could increase to about $70 \%$.In general, its energy saving potential accounted for $10 \%$ to $20 \%$ of the total energy saving potential of the refinery.

Although a lot of manpower and material resources were invested to carry on the transformation to the low temperature waste heating(below $50{ }^{\circ} \mathrm{C}$ ) use system during China's "Eleventh Five-Year" period, but depending on the energy-intensive characteristic, more cost-effective investments for energy system optimization may be a useful strategy to improve the competitiveness of China's refining industry.

Based on the current situation of the petroleum refining industry, in this study, a water source cascade heat pump system using a new binary near-zeotropic refrigerant named BY-3 ${ }^{[15]}$ and R245fa as working fluid in the low-stage and high -stage refrigeration cycle, respectively, was studied numerically and experimentally. The system was simulated at different water inlet temperature and the simulated results were validated by the experimental results with high accuracy.

\section{Methodology}

\subsection{Working principle of HTCHP system}

The working principle for the cascade heat pump system is:

a. For the low-stage refrigerant cycle, the new near-zeotropic mixture named BY-3 absorbs heat in the evaporator while evaporating. The low pressure and temperature BY-3 vapor comes out from the evaporator is then compressed in the hermetic scroll compressor made by Danfoss into high pressure and temperature vapor. The BY-3 vapor discharges from the low-stage cycle compressor then releases heat in the low-stage cycle condenser and turns into 
liquid with high pressure and temperature. Then the liquid goes into the EEV

of the low-stage cycle and changes to liquid with low pressure and temperature, and then the liquid goes into the low-stage cycle evaporator to finish the low-stage refrigerant cycle.

b. For the high-stage refrigerant cycle, the working fluid R245fa absorbs heat in the evaporator while evaporating. The low pressure and temperature R245fa vapor comes out from the evaporator is then compressed in the hermetic scroll compressor made and modified by Danfoss into high pressure and temperature vapor. The R245fa vapor discharges from the high-stage cycle compressor then releases heat in the high-stage cycle condenser and turns into liquid with high pressure and temperature. Then the liquid goes into the EEV of the high-stage cycle and changes to liquid with low pressure and temperature, and then the liquid goes into the high-stage cycle evaporator to finish the high-stage refrigerant cycle.

The P-h and T-s diagram of the cascade system are shown in Fig.1 and the heat flow of a cascade heat pump system is shown in Fig. 2. 
109

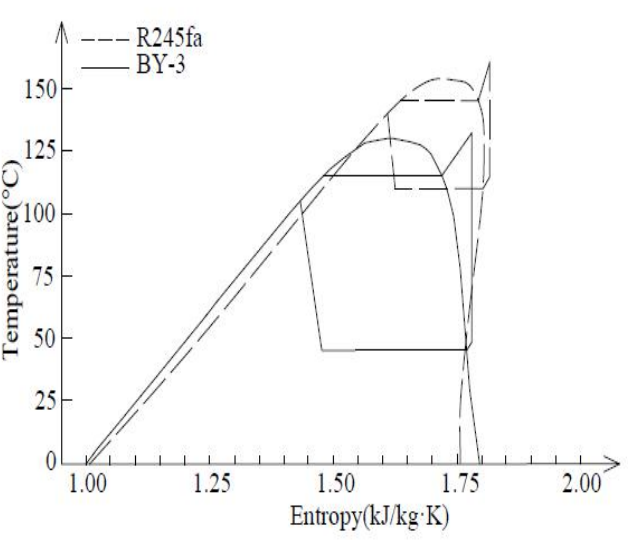

Fig.1. P-h and T-s diagram of cascade cycle

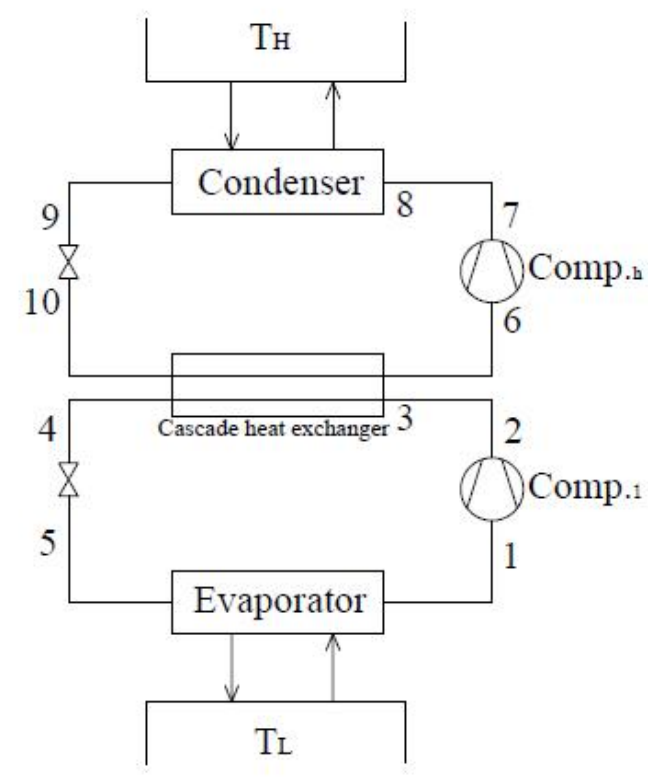

111

112

113

114

115

116 of the cascade system: evaporator, cascade heat exchanger, condenser, high-stage and low-stage compressor, high-stage and low-stage EEV.

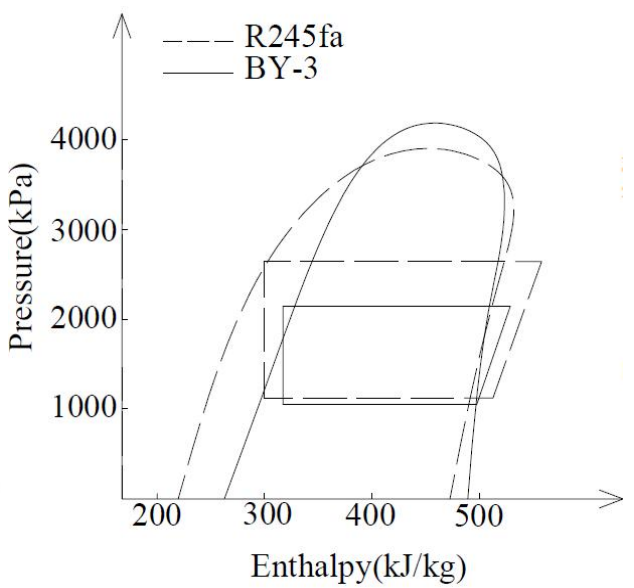


(1) The refrigerants in the cascade heat pump are in steady state.

(2) Refrigerants are saturated at the outlet of the evaporator, the cascade heat exchanger and the condenser.

(3) The heat dissipation from the cascade heat exchangers and pipes to environment is negligible, i.e. the heat released from the low-temperature water is totally transferred to the refrigerant in the low-stage refrigerant cycle.

(4) The pressure loss in heat exchangers and the pipes is negligible.

(5) The compression in the compressors is isentropic.

According to the hypotheses mentioned above, the conservation of the mass and energy formula of the refrigerant can be acquired as shown in Eq.(1).and Eq.(2).

$$
\sum_{\text {in }} \mathrm{m}=\sum_{\text {out }} \mathrm{m}
$$

$$
\mathrm{Q}-\mathrm{W}+\sum_{\text {in }} \mathrm{mh}-\sum_{\text {out }} \mathrm{mh}=0
$$

\subsubsection{Evaporator in the low-stage cycle}

According to the principle described above, the heat transfer in the low-stage cycle can be described in:

Low temperature heat source side:

$$
\mathrm{Q}_{\mathrm{l}}=\mathrm{c}_{\mathrm{w}} \mathrm{m}_{\text {evap,w}}\left(\mathrm{t}_{\text {evap,w,in }}-\mathrm{t}_{\text {evap,w,out }}\right)
$$

$$
\text { Refrigerant side: }
$$

$$
\mathrm{Q}_{\mathrm{l}}=\left(\mathrm{h}_{5}-\mathrm{h}_{1}\right) m_{l, r e f}
$$

\section{(4)}


141 cycle can be described as:

$142 \quad \mathrm{~m}_{\mathrm{l}, \mathrm{ref}}=\frac{\mathrm{Q}_{\mathrm{l}}}{\mathrm{h}_{5}-\mathrm{h}_{1}}$

143 The specific heat of water $\left(C_{w}\right)$ in Eq.3 is shown in Eq.6, and based on a 144 regression analysis, the correlation coefficient can be $100 \%$ in high temperature zone of $60-145^{\circ} \mathrm{C}^{[16]}$.

\section{Eq.7:}

$149 \quad \mathrm{C}_{\mathrm{w}}=\frac{\mathrm{C}_{, \mathrm{w}}\left(\mathrm{t}_{\mathrm{w}, \text { in }}\right)+\mathrm{C}_{\mathrm{w}}\left(\mathrm{t}_{\mathrm{w}, \text { out }}\right)}{2}$

2.2.2 Hermetic scroll compressor

Hermetic scroll compressors were chosen in this paper due to the excellent properties such as simple structure, high reliability, low vibration, high efficiency, and

153 low noise ${ }^{[17]}$. cycle is described in Eq.8 and 9:

$P_{\text {in, } 1}=\frac{p_{\text {theo, } 1}}{\eta_{\mathrm{s}} \eta_{\mathrm{e}} \eta_{\mathrm{m}}}=\frac{\mathrm{m}_{\mathrm{ref}, 1}\left(\mathrm{~h}_{2}-\mathrm{h}_{1}\right)}{\eta_{\mathrm{s}} \eta_{\mathrm{e}} \eta_{\mathrm{m}}}$

$P_{\text {in }, \mathrm{h}}=\frac{\mathrm{p}_{\text {theo, } \mathrm{h}}}{\eta_{\mathrm{s}} \eta_{\mathrm{e}} \eta_{\mathrm{m}}}=\frac{\mathrm{m}_{\mathrm{ref}, \mathrm{h}}\left(\mathrm{h}_{7}-\mathrm{h}_{6}\right)}{\eta_{\mathrm{s}} \eta_{\mathrm{e}} \eta_{\mathrm{m}}}$ 
160 inlet and outlet of the high-stage cycle compressor and $\eta_{\mathrm{s}}, \eta_{\mathrm{m}}$ and $\eta_{\mathrm{e}}$ refer to the 161 isentropic efficiency (refers to AHRI540-2004 standard rating condition), the 162 volumetric efficiency and the motor efficiency, and normally the values for fixed 163 speed scroll compressor are $0.7,0.8$ and 0.85 , respectively.

164

\subsubsection{Cascade heat exchanger}

Condenser in the low-stage refrigerant cycle:

$$
\mathrm{Q}_{\text {cond, } 1}=\mathrm{m}_{1_{\text {ref }}}\left(\mathrm{h}_{3}-\mathrm{h}_{4}\right)
$$

Where $h_{3}$ and $h_{4}$ refers to the enthalpy at the inlet and outlet of the condenser in the low-stage refrigerant cycle.

Evaporator in the high-stage refrigerant cycle:

$$
\mathrm{Q}_{\text {evap , h }}=\mathrm{m}_{\text {ref, } \mathrm{h}}\left(\mathrm{h}_{10}-\mathrm{h}_{6}\right)
$$

\subsubsection{Condenser}

Water side:

$$
\mathrm{Q}_{\mathrm{h}}=\mathrm{C}_{\text {cond,w,h }}\left(\mathrm{t}_{\text {cond,w,out,h }}-\mathrm{t}_{\text {cond,w,in, } \mathrm{h}}\right)
$$

Where $\mathrm{Q}_{\mathrm{h}}, \mathrm{C}_{\text {cond,w,h }}, \mathrm{t}_{\mathrm{cond}, \mathrm{w}, \mathrm{out}, \mathrm{h}}$ and $\mathrm{t}_{\mathrm{cond}, \mathrm{w}, \mathrm{in,h}}$ refers to the heating capacity in the high-stage refrigerant cycle, the specific heat of the water in the condenser in the high-stage refrigerant cycle, the water temperature at the outlet and inlet of the condenser in the high-stage refrigerant cycle, respectively.

$$
\text { Refrigerant side: }
$$

$$
\mathrm{Q}_{\mathrm{h}}=\mathrm{m}_{\mathrm{ref}, \mathrm{h}}\left(\mathrm{h}_{8}-\mathrm{h}_{9}\right)
$$


182

183

184

$190 \quad \mathrm{COP}=\frac{\mathrm{Q}_{\mathrm{h}}}{\mathrm{P}}=\frac{\mathrm{Q}_{\mathrm{h}}}{\mathrm{P}_{\mathrm{in}, 1}+\mathrm{P}_{\mathrm{in,h}}}$

Eq.13 and14.

$$
\mathrm{m}_{4}=\mathrm{m}_{5}=\mathrm{m}_{1, \text { ref }}
$$$$
\mathrm{h}_{4}=\mathrm{h}_{5}
$$
Eq.13 and 14.

$$
\begin{aligned}
& \mathrm{m}_{9}=\mathrm{m}_{10}=\mathrm{m}_{\mathrm{h}, \text { ref }} \\
& \mathrm{h}_{9}=\mathrm{h}_{10}
\end{aligned}
$$

For the high-stage cycle, the refrigerant mass and enthalpy can be described in

According to the precious analysis, COP can be obtained as below.

\section{Test rig setup}

\subsection{Refrigerant and test rig}

Refrigerant is very important in the HTCHP system which can affect the performance and the safe-operation, etc., and during the selection of the refrigerant some rules need to be considered ${ }^{[18-20]}$, such as eco-friendly, good at thermodynamics, flammability and toxicity. According to these concerns, a new near-zeotropic mixture named BY-3 was proposed as the working fluid in the low-stage refrigerant cycle, and R245fa was proposed to use in the high-stage refrigerant cycle. The basic properties for BY-3 and R245fa are shown in Table 1.The properties of the refrigerant in this paper are using the data from the software NISTREFPROP9.1. 


\begin{tabular}{lccccc}
\hline Substance & $\mathrm{T}_{\mathrm{c}}\left({ }^{\circ} \mathrm{C}\right)$ & $\mathrm{P}_{\mathrm{c}}\left(\mathrm{MP}_{\mathrm{a}}\right)$ & $\mathrm{ODP}$ & $\mathrm{GWP}(100 \mathrm{yr})$ & Security Level \\
\hline BY-3 & 126.2 & 4.664 & 0.04 & 2100 & $\mathrm{~A}^{\mathrm{a}} 1^{\mathrm{b}}$ \\
$\mathrm{R} 245 \mathrm{fa}$ & 154.01 & 3.65 & 0 & 950 & $\mathrm{~B}^{\mathrm{a}} 1^{\mathrm{b}}$ \\
\hline
\end{tabular}

202

203

204

205

206

207

208

209

210

211

212

213

214

Note: a, According to TLV-TWA ${ }^{[21]}$, while the refrigerant concentration is equal to or less than $400 * 10^{-4} \%$, it is non-toxic; $\mathrm{b}$, There is no flame spreading in the air if the refrigerant is tested under the condition of $102.3 \mathrm{kPa}$ and $21^{\circ} \mathrm{C}$.

Based on the physical parameters of BY-3, a regression analysis was done and shown in Eq.19-20. The analysis results suggested the correlation coefficients are 99. $87 \%$ and $99.89 \%$ for liquid and vapor, respectively.

$$
\begin{gathered}
\mathrm{h}_{\mathrm{l}, \mathrm{BY} 3}=9 \times 10^{-5} t^{3}-1.05 \times 10^{-2} \times t^{2}+2.552 \times t+191.72 \\
\mathrm{~h}_{\mathrm{v}, \mathrm{BY} 3}=-1 \times 10^{-4} \mathrm{t}^{3}+1.74 \times 10^{-2} \mathrm{t}^{2}-2.068 \times 10^{-1} \mathrm{t}+515.07
\end{gathered}
$$

A regression analysis was also done based on the physical parameters of R245fa as shown in Eq.21-22.The analysis results suggest that the correlation coefficients are $99.88 \%$ and $99.92 \%$ for liquid and vapor, respectively.

$$
\begin{array}{r}
\mathrm{h}_{\mathrm{l}, \mathrm{R} 245 \mathrm{fa}}=5 \times 10^{-5} t^{3}-1.17 \times 10^{-2} \times t^{2}+2.3858 \times t+167.74 \\
\mathrm{~h}_{\mathrm{v}, \mathrm{R} 245 \mathrm{fa}}=-8 \times 10^{-5} \mathrm{t}^{3}+2.14 \times 10^{-2} \mathrm{t}^{2}-1.1363 \times 10^{-1} \mathrm{t}+451.47
\end{array}
$$

The t-h diagram of BY-3 and R245fa is shown in Fig 3 and4. 


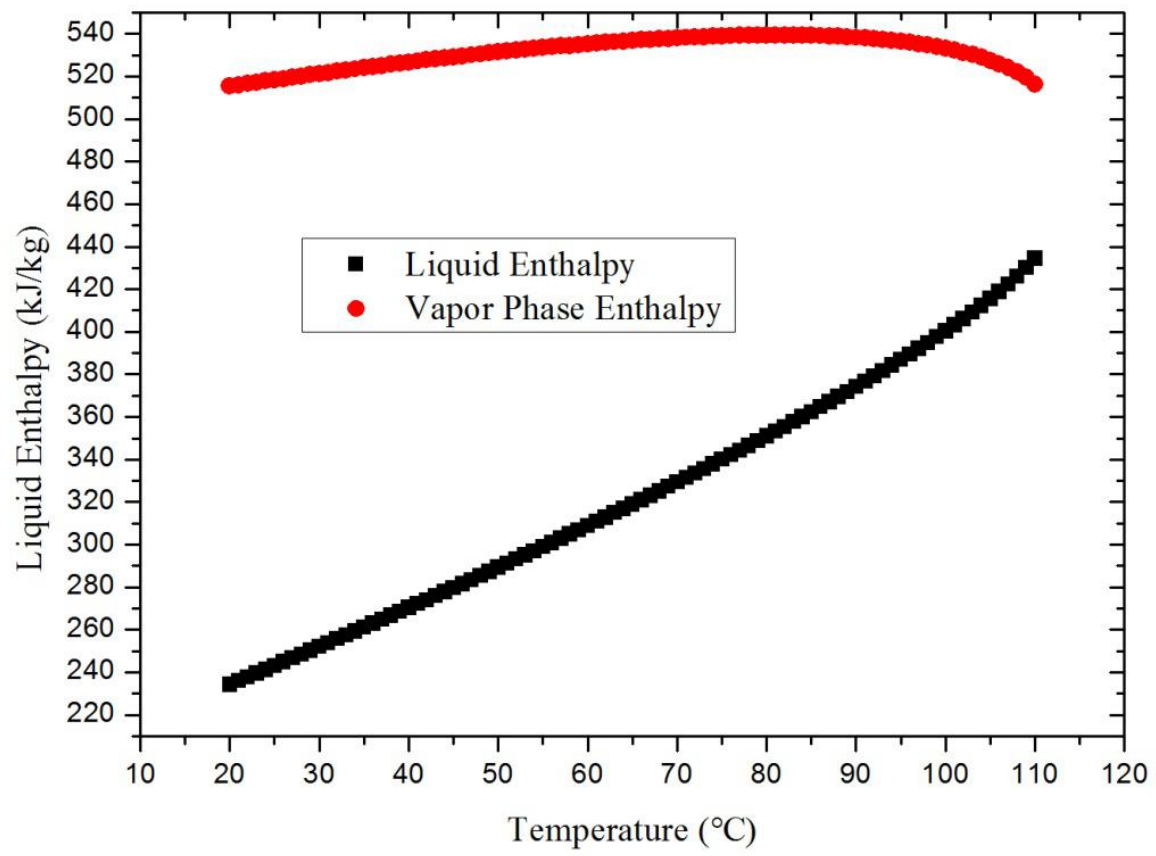

Fig.3. t-h diagram of BY-3

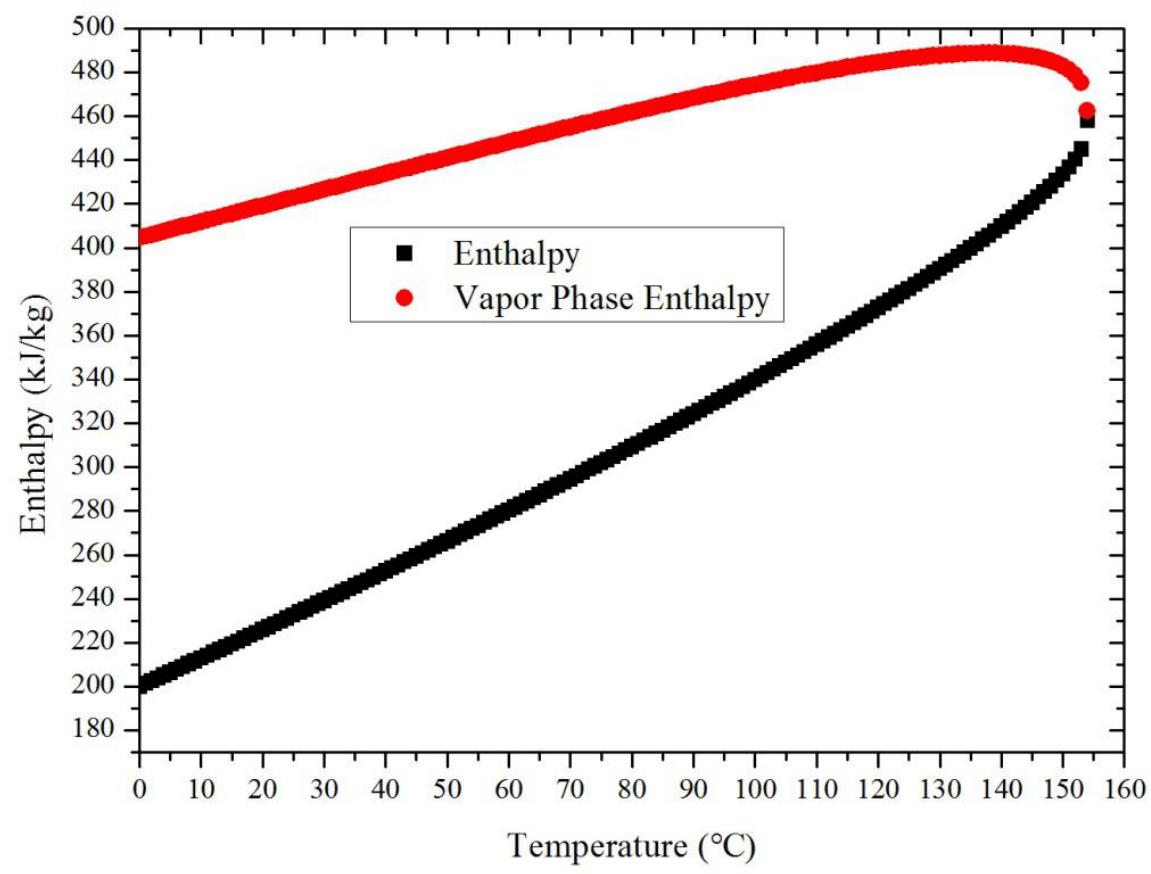

Fig.4. t-h diagram of R245fa

220 Based on the theoretical analysis above, one test rig was designed in this research 
222 independent parts: the refrigerant cycle consisted of the low-stage refrigerant and the

223 high-stage refrigerant cycle; a low-temperature water tank with an electric heater

224 which can supply water at the constant temperature so that the evaporating

225 temperature in the evaporator could be controlled and a hermetic high temperature

226 water reservoir was used to support the high-temperature water cycle. The schematic

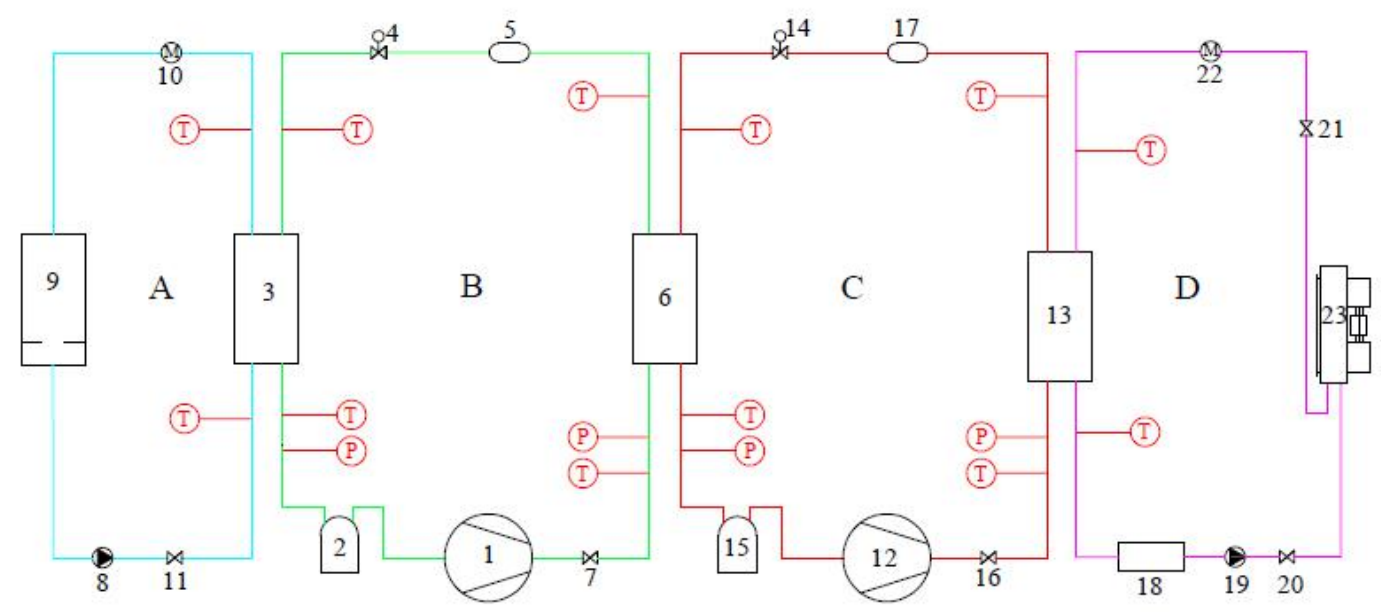

1 Low-stage cycle compressor

2 Gas-liquid seperator

3 Low-stage cycle evaporator

4 Low-stage cycle EEV

5 Drying-filter

6 Cascade heat exchanger

7 Regulating valve

8 Water pump

9 Water tank with electric heater

10 Heater meter

11 Regulating valve
12 High-stage cycle compressor 13 High-stage cycle condenser

14 High-stage cycle EEV

15 Gas-liquid seperator

16 Regulating valve

17 Drying-filter

18 Water tank

19 Water pump

20 Regulating valve

21 Exhaust valve

22 Water flowmeter

23 Fan-coil

Fig.5. Schematic diagram of the HTCHP test rig

230 The refrigerant liquid in the low-stage cycle absorbed heat from the

231 low-temperature water and turned into vapor, and then the low temperature and

232 pressure refrigerant vapor was compressed in the low-stage cycle compressor into 
cycle was a double-pipe heat exchanger so that the long flow path can make sure that

235 the refrigerant in the low and high-stage cycle can change heat sufficiently. The low

236 temperature and pressure refrigerant liquid (R245fa) in the high-stage cycle absorbed

237 heat from the high temperature and pressure BY-3 vapor and then was compressed in

238 the high-stage cycle compressor into high temperature and pressure vapor. And then

239 the heat was transferred to the water in the fan coil. In order to reduce the heat

240 emitting to the environment, all the pipes of the cascade system are packaged with

241 thermal insulation material.

242 The compressors used in this research were made and modified by Danfoss. The

243 specification of the compressors and heat exchangers is shown in Table 2 and 3.

244 Table2: Parameters of the compressors used in the cascade experimental system

\begin{tabular}{|c|c|c|c|c|c|c|c|c|c|}
\hline Unit & Model & \multicolumn{2}{|r|}{$\begin{array}{l}\text { Manufactur } \\
\mathrm{e}\end{array}$} & $\begin{array}{l}\text { Rated } \\
\text { Load } \\
\text { Amps(A } \\
\quad)\end{array}$ & \multicolumn{2}{|c|}{$\begin{array}{l}\text { Cooling } \\
\text { capacity( } \\
\text { w) } \\
\text { @ARI } \\
\text { 50HZ }\end{array}$} & $\begin{array}{l}\text { Power } \\
\text { input(kW } \\
\text { ) @ARI } \\
50 \mathrm{HZ}\end{array}$ & $\begin{array}{l}\text { Swept } \\
\text { volume } \\
(\mathrm{cm} 3 / \mathrm{rev} \\
\text { ) }\end{array}$ & $\begin{array}{l}\text { Pressur } \\
\mathrm{e} \\
\text { vessel } \\
\text { code }\end{array}$ \\
\hline $\begin{array}{l}\text { BY-3\&R245 } \\
\text { fa } \\
\text { Compressor }\end{array}$ & \multicolumn{2}{|c|}{$\begin{array}{l}\text { SH090A4AL } \\
\text { C }\end{array}$} & Danfoss & 14.3 & \multicolumn{2}{|c|}{22490} & 7.215 & 88.4 & PED \\
\hline \multicolumn{10}{|c|}{ Table 3: Parameters of the heat exchangers } \\
\hline Unit & Model & $\begin{array}{l}\text { Des } \\
\text { pre } \\
\text { ar) }\end{array}$ & $\begin{array}{l}\text { sign } \\
\text { ssure(B }\end{array}$ & $\begin{array}{l}\text { Design } \\
\text { temperatur } \\
\left.{ }^{\circ} \mathrm{C}\right)\end{array}$ & \multicolumn{3}{|c|}{$\begin{array}{l}\text { Relative } \\
\text { directions of } \\
\text { fluids }\end{array}$} & $\begin{array}{l}\text { Heat } \\
\text { Exchang } \\
\text { ed } \\
(\mathrm{kW})\end{array}$ & $\begin{array}{l}\text { Pressu } \\
\text { re } \\
\text { vessel } \\
\text { code }\end{array}$ \\
\hline $\begin{array}{l}\text { evaporat } \\
\text { or }\end{array}$ & $\begin{array}{l}\text { CB60-26 } \\
M\end{array}$ & 40 & & $-196.0 / 225$ & \multicolumn{3}{|c|}{$\begin{array}{ll}.0 & \text { Countercurr } \\
\text { ent }\end{array}$} & 20 & PED \\
\hline $\begin{array}{l}\text { Cascade } \\
\text { heat } \\
\text { exchang } \\
\text { er }\end{array}$ & $\mathrm{n} / \mathrm{a}$ & 40 & & $-196.0 / 225$ & \multicolumn{3}{|c|}{$\begin{array}{ll}0 & \text { Countercurr } \\
\text { ent }\end{array}$} & 25 & PED \\
\hline Condens & CB60-32 & 40 & & $-196.0 / 225$ & \multicolumn{3}{|c|}{ Countercurr } & 36 & PED \\
\hline
\end{tabular}


\begin{tabular}{lll}
\hline er & $\mathrm{L}$ & ent
\end{tabular}

3.2 Compressor setup for high-stage cycle

Two hermetic scroll compressors were used in this research. Some necessary modifications were done in the model shop of Danfoss in order to meet the high discharge temperature in the high-stage cycle.

The scroll compressor is designed to compress the refrigerant gas with low pressure and temperature to high pressure and high temperature state. The orbiting and fixed scrolls are in the upside of the compressor, and the compression process of the refrigerant gas is proceeding in these two scrolls. The working process in the compressor can be described into three steps: suction, compression and discharge as shown in Fig.6. The compressor working in the high discharge application will cause the distortion of scrolls and further lead to serious worn and unexpected compressor motor trapped. In order to avoid this kind of issue, the scroll assembly setting was changed. The clearance between the orbiting and fixed scrolls was enlarged $10 \sim 20$ $\mu \mathrm{m}$, which could compensate the scroll heat extension, and it was useful to avoid the worn and increase the compressor reliability.

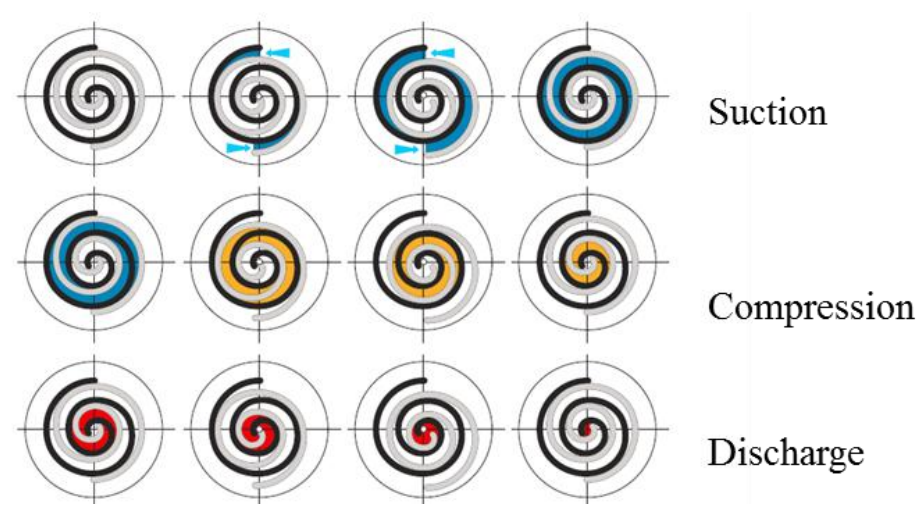

Fig.6.Refrigerant compressing process in the scroll The protector parameter of the compressor motor in the high-stage cycle need to 
be adjusted since that the high-stage compressor worked in a high suction temperature

265 which will cause the unexpected compressor motor trapped. Normally, the set for 266 motor protector is $85-115^{\circ} \mathrm{C}$, which means if the suction temperature is higher than

$267115^{\circ} \mathrm{C}$, the protector will be trapped and the compressor stops working, and when the 268 motor temperature is lower than $85^{\circ} \mathrm{C}$, the circuit will become close again so that the 269 compressor can be restarted. In this paper, the protector parameter of the high-stage 270 cycle was changed to $115-145^{\circ} \mathrm{C}$ according to the working condition.

271 In order to adapt the high discharge temperature in the high-stage cycle, a

272 high-temperature applicative lubricant was used in this research.

273 Table 4 The properties of lubricant used in high-stage cycle

\begin{tabular}{lccccc}
\hline Item & $\begin{array}{c}\text { Kinematic } \\
\text { viscosity }\left(40^{\circ} \mathrm{C}\right)\end{array}$ & Pour point & $\begin{array}{c}\text { Water } \\
\text { content }\end{array}$ & $\begin{array}{c}\text { Density } \\
\left(15^{\circ} \mathrm{C}\right)\end{array}$ & Specific Resistance \\
\hline unit & $\mathrm{mm}^{\wedge} 2 / \mathrm{s}$ & ${ }^{\circ} \mathrm{C}$ & $\mathrm{ppm}$ & $\mathrm{g} / \mathrm{m}^{\wedge} 3$ & $\mathrm{~T} \Omega \mathrm{m}$ \\
specification & $61.2-74.8$ & -30 & 200 & $0.929-0.945$ & 0.01 \\
\hline
\end{tabular}

3.3 Measurement equipment and data acquisition pressure were all sent to Agilent 34972A data acquisition machine for further analysis. The values of power consumption and heat meter were recorded in the same time with the temperatures. The parameters of the measurement equipment are shown in Table $\mathbf{5}$ as follows:

Table5: Parameters of the measurement equipment used in the cascade experimental system

\begin{tabular}{llll}
\hline Part & model & accuracy & comment \\
\hline Pt100 & $\mathrm{n} / \mathrm{a}$ & $+/-0.3^{\circ} \mathrm{C}$ & $\mathrm{n} / \mathrm{a}$ \\
\hline
\end{tabular}




\begin{tabular}{llll} 
Pressure transducer(suction) & HSTL-800A,0-1.5MPa & $0.2 \% \mathrm{~F} . \mathrm{S}$ & Beijing Zhong xing \\
& & & Ltd. corp \\
Pressure & HSTL-800A,0-5.0MPa & $0.2 \% \mathrm{~F} . \mathrm{S}$ & Beijing Zhong xing \\
transducer(discharge) & & & Ltd. corp \\
Heat meter & IC-3 & $+/-2 \%$ & Yidu \\
Mass flowmeter & HH-LUCB-32 & 1.0 grade & Huai an \\
Power meter & DED194E-9SYK02 & $+/-(0.5 \%+1)$ & Shanghai Dingde \\
Data acquisition & $34972 \mathrm{~A}$ & $\mathrm{n} / \mathrm{a}$ & Agilent \\
\hline
\end{tabular}

284 Type $\mathrm{B}^{[22]}$. And the uncertainty discussed in this paper is relative overall uncertainty.

285 The basic equation of uncertainty analysis ${ }^{[23]}$ is shown in Eq. (19).

$$
\delta R=\left\{\sum_{i=1}^{N}\left(\frac{\delta R}{\delta X_{i}} \delta X_{i}\right)^{2}\right\}^{1 / 2}
$$

Where $\mathrm{Xi}, \delta \mathrm{Xi}$ and $\delta \mathrm{R}$ refers to the measurement value, the uncertainty of $\mathrm{Xi}$ and the overall uncertainty, respectively.

The maximum relative overall uncertainties of $\mathrm{COP}$ and heating capacity are

$4.15 \%$ and $4.30 \%$, respectively.

\section{Results and discussion}

4.1 Experimental results and discussion 


\section{temperature in high-stage refrigerant cycle}

Fig7 shows the experimental results (water inlet temperature at $50{ }^{\circ} \mathrm{C}$ ) at the optimum refrigerant charge amount of R245fa equals to $3400 \mathrm{~g}$ and BY-3 equals to $2000 \mathrm{~g}$ in the low \& high-stage refrigerant cycle, respectively. From Fig 7-a, we can see that with the water outlet temperature increasing, the input power in both low-stage and high-stage refrigerant cycle increased accordingly due to the compression ratio increased in the low and high-stage refrigerant cycle. From Fig7-d, it could be found that the evaporating temperature in high-stage refrigerant cycle kept nearly stable before the water outlet temperature reached $115^{\circ} \mathrm{C}$, and then it increased according to the water outlet temperature. Consequently, the heating capacity increased firstly and then when the water outlet temperature reached $115^{\circ} \mathrm{C}$, the heating capacity decreased according to the water outlet temperature increasing. The temperature difference between DT in high-stage and water outlet temperature is about $5-6{ }^{\circ} \mathrm{C}$, and the value increased a little when the water outlet temperature reached $130{ }^{\circ} \mathrm{C}$ due to the decreasing latent heat of the refrigerant. The total COP of the HTCHP decreased according to the increasing of the water outlet temperature in the high-stage cycle condenser due to the input power and heating capacity changing. 


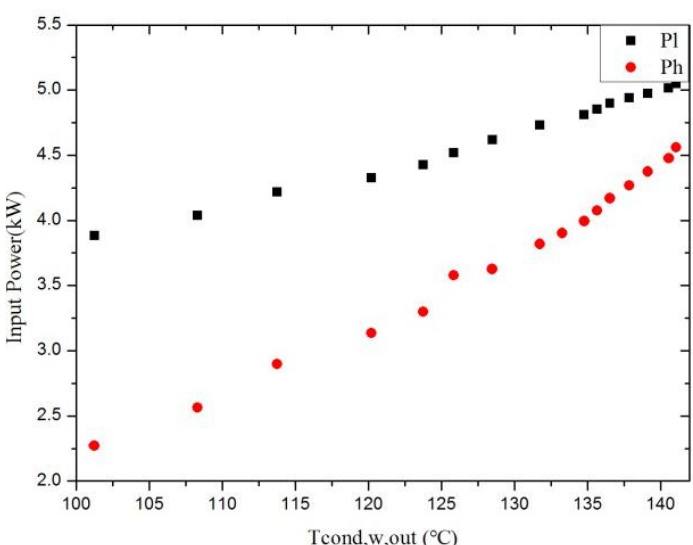

(a) Input Power

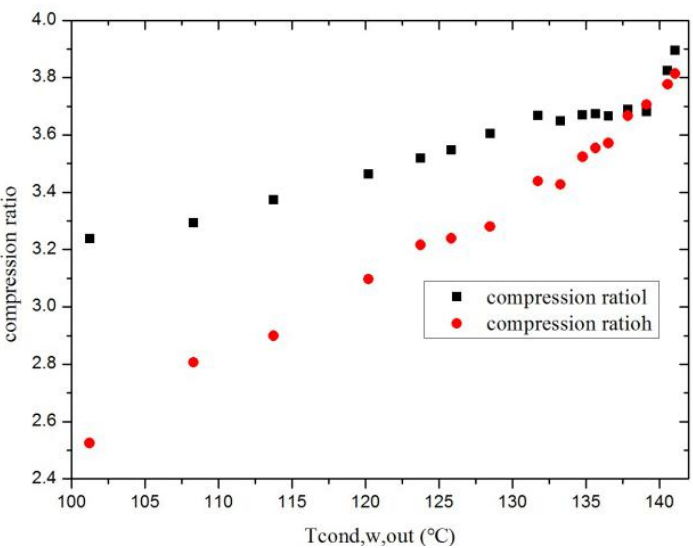

(c) compression ratio

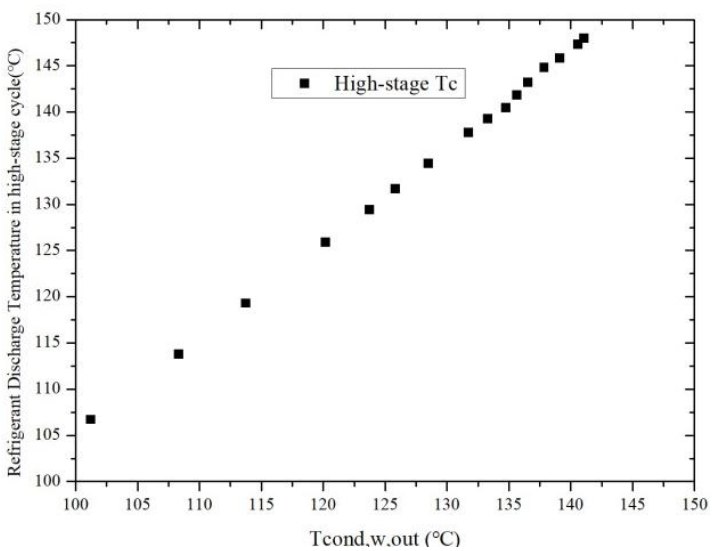

(e) High-stage DT

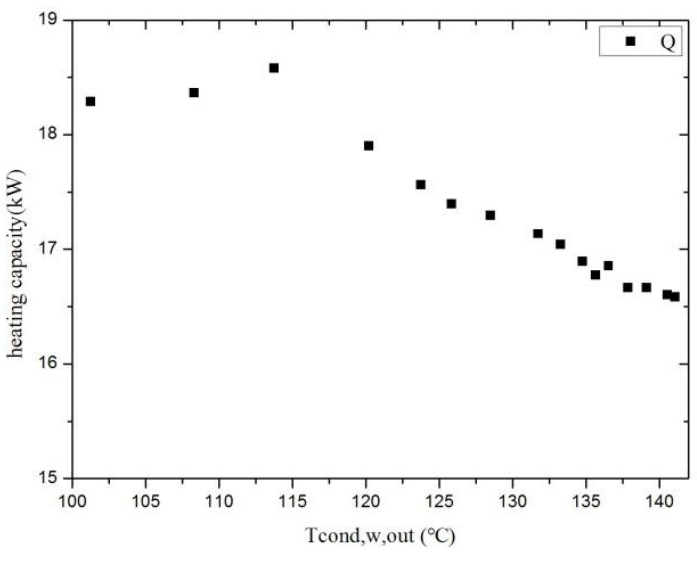

(b) heating capacity

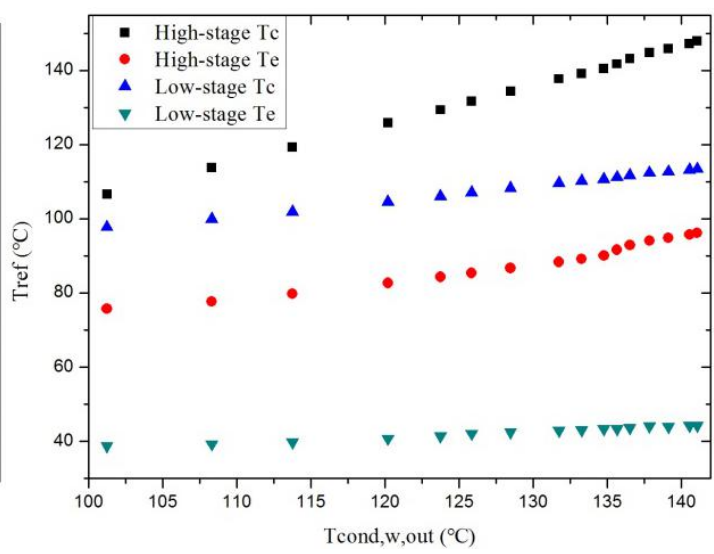

(d) refrigerant temperature

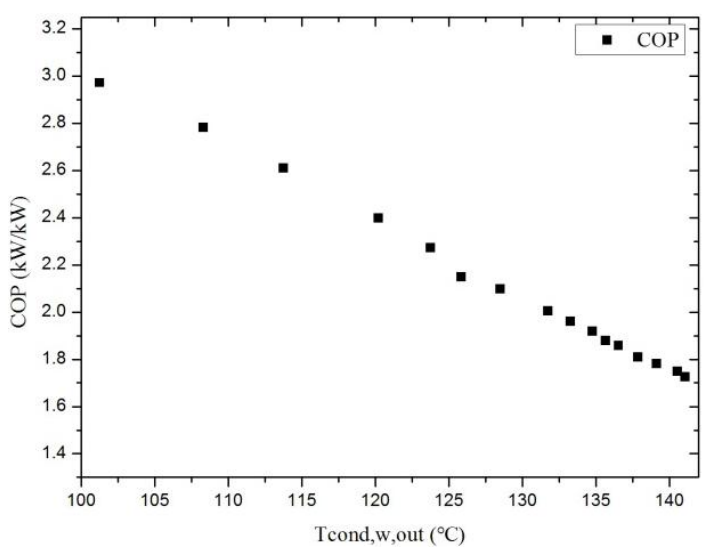

(f) $\mathrm{COP}$

Fig. 7. Variations of (a) Input Power, (b) heating capacity,(c) compression ratio, (d) refrigerant 
322 The performance of the cascade system was investigated by changing the water

323 inlet temperature in the evaporator of the low-stage cycle at the optimum refrigerant

324 charge amount of $3400 \mathrm{~g}$ and $2000 \mathrm{~g}$ in the low-stage and high-stage refrigerant cycle,

325 respectively. The water flow rate in the low-stage cycle was fixed at $1630 \mathrm{~kg} / \mathrm{h}$.

326

327

328

329

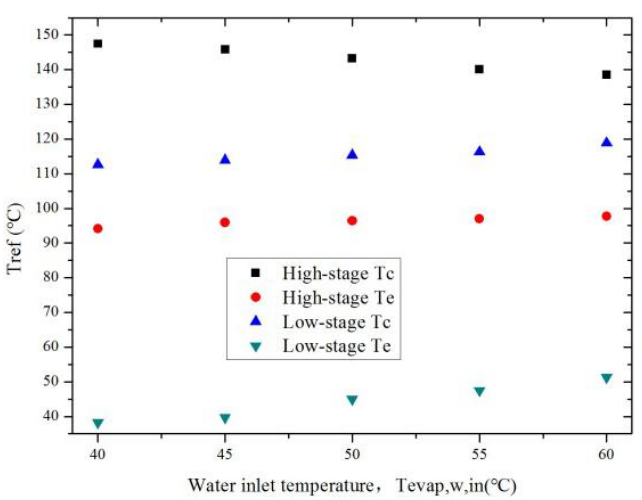

(a) refrigerant temperature

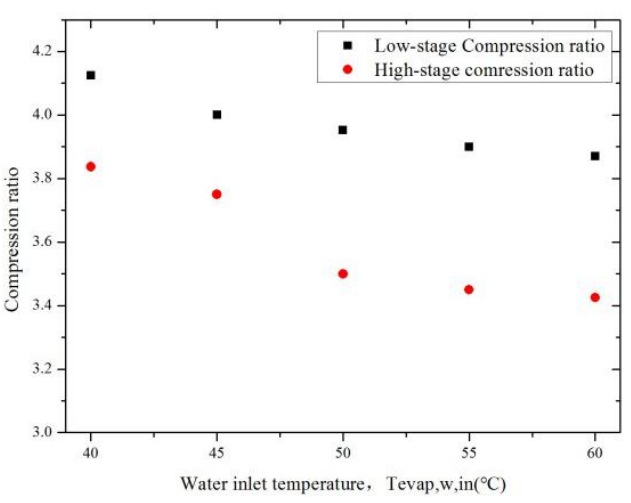

(c) compression ratio

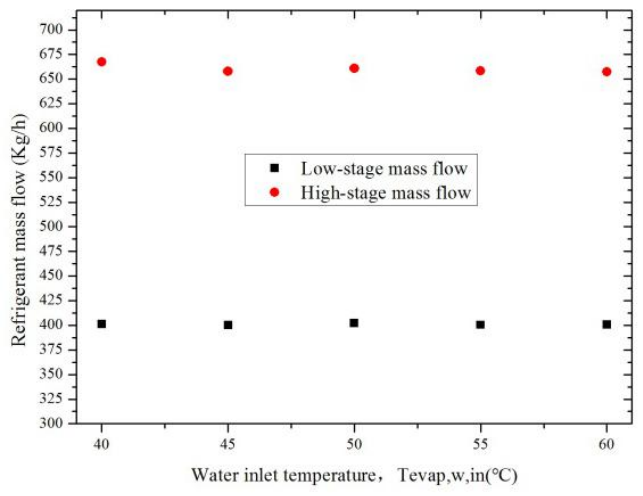

(b) mass flow

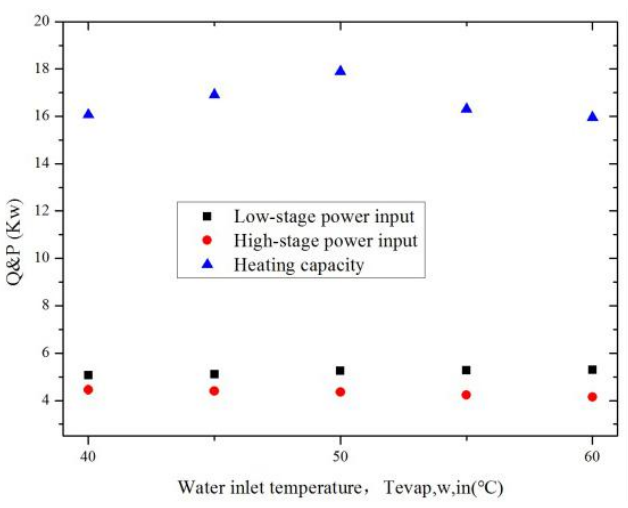

(d) power input and heating capacity 


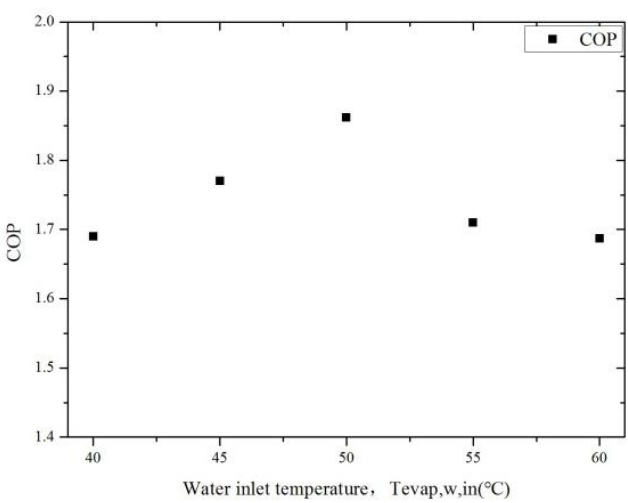

(e) COP

Fig.8.Variations of (a) refrigerant temperature (b) mass flow and(c) compression ratio (d) power input and heating capacity (e) COP according to the water inlet temperature in the low-stage evaporator

As shown in Fig.8, the change of the refrigerant temperatures, the refrigerant mass flow, the compression ratio, input power and heating capacity and COP according to the water inlet temperature were studied.

The low-stage cycle evaporating temperature increased due to the increasing water inlet temperature. The condensing temperature in the low-stage cycle increased according to the water inlet temperature and the rate of the condensing temperature is less than the evaporating temperature due to the decreasing compression ratio in the low-stage cycle as shown in Fig.8-c. The high-stage cycle evaporating temperature increased due to the increasing condensing temperature in the low-stage cycle according to the water inlet temperature. The high-stage cycle condensing temperature decreased due the decreasing rate of the compression ratio in the high-stage cycle is larger than the increasing ratio of the evaporating temperature in the high-stage cycle.

The input power in the low and high-stage cycle kept nearly the same due to the constant refrigerant mass flow. The heating capacity of the cascade system increased firstly and when the water inlet temperature reached $50^{\circ} \mathrm{C}$, it reached the maximum 
and then it decreased according to the water inlet temperature increasing because of

350 the compressor running map(at the same evaporating temperature, when the

351 condensing temperature increases, power input will increase while the cooling

352 capacity will decrease ). Accordingly, the COP of the cascade heat pump system

353 followed the same tendency as the heating capacity.

$354 \quad 4.2$ Simulated results

355

356

357

358

359

360

temperature

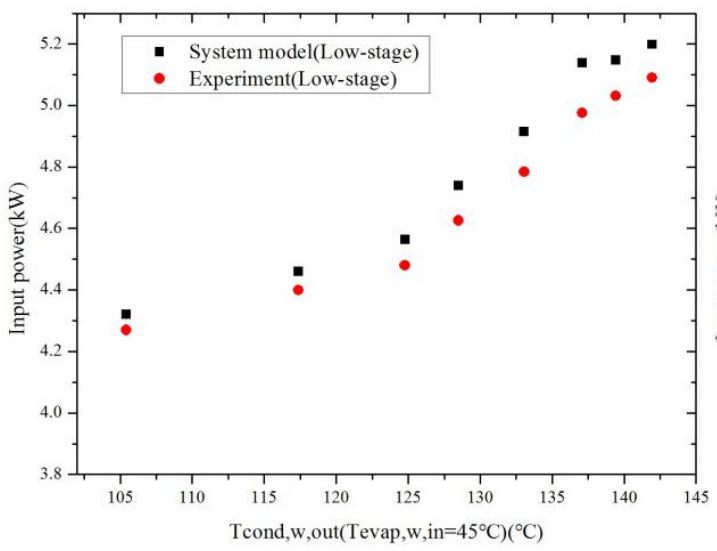

(a) Input power in low-stage results.
361

\subsubsection{Model validation}

were shown in Fig.

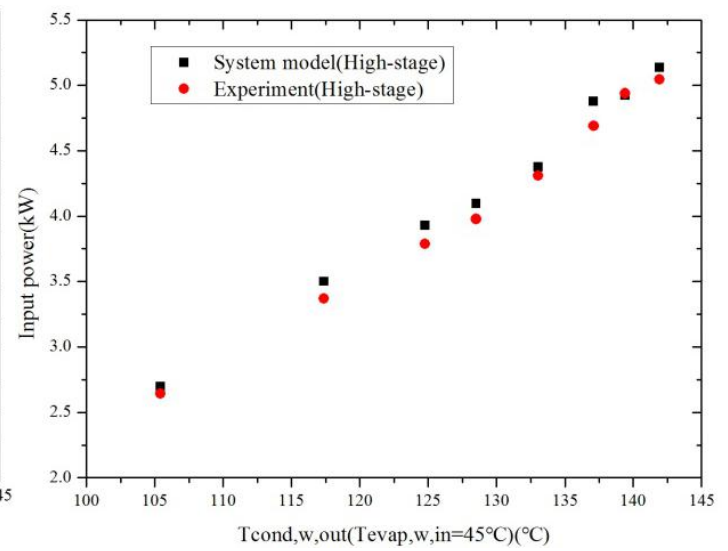

(b) Input power in high-stage

The presented model was verified comparing the experimental and simulated

The input power (low-stage and high-stage), heating capacity and COP of experiment and system model according to outlet water temperature (with water inlet 


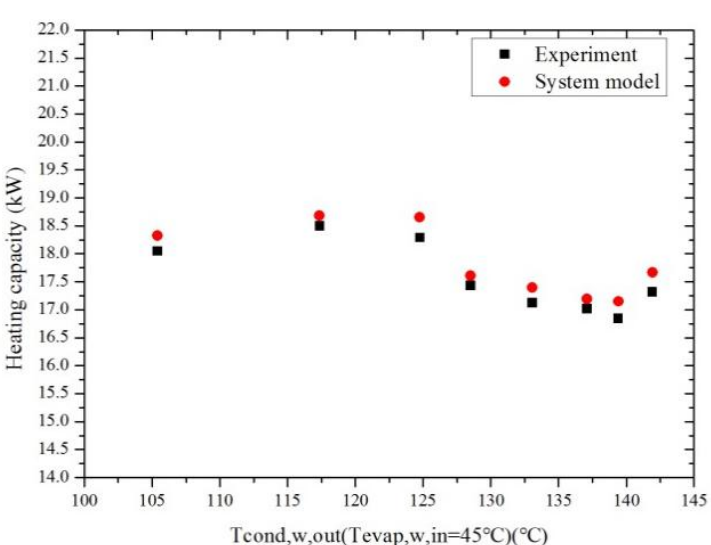

(c) Heating capacity

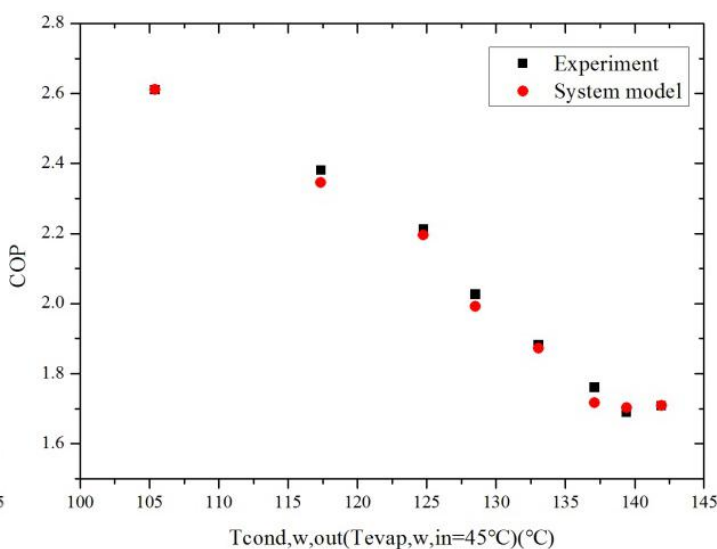

(d) COP

Fig.9 Comparisons of System model and Experimental results of (a) Input power in low-stage (b)

Input power in high-stage (c) Heating capacity (d) COP according to the water outlet temperature

In Fig.9, the changing current of the system model results of the input power,

heating capacity and COP followed the same tendency with that of the experimental

results. In the low-stage refrigeration cycle, the system model of the input power was

higher than that of the experimental results with the maximum relative deviation of cycle was a little higher than that of the experimental result and the maximum deviation is $3.93 \%$. The heating capacity of the system model was higher than that of

374 the experimental result with the maximum deviation of $1.96 \%$. Consequently, the 375 COP of the system model was lower than the experimental result and the maximum 376 deviation was $-2.53 \%$. In this case, the system model was validated with the 377 experimental result.

\section{Conclusions}


and the following conclusions could be drawn based on the results discussed before:

(1) The experimental results showed that the cascade heat pump system could reach water outlet temperature of $142{ }^{\circ} \mathrm{C}$ and the maximum temperature lift could reach $100{ }^{\circ} \mathrm{C}$ which was the highest level in the opening literature. BY-3 was proved to have good performance as the working fluid in the low-stage refrigeration cycle. The pressure ratio in the high and low-stage refrigeration cycle was 3.4 and 3.9, respectively with the system COP of 1.72.

(2) The system model was validated with high feasibility via the experimental results. The maximum relative deviation of input power in high \& low-stage, the heating capacity and the COP between the system model and the experimental results was $3.93 \%, 3.27 \%, 1.96 \%$ and $-2.53 \%$, respectively.

\section{Acknowledgements}

This study is supported by the 973 National Basic Research Program of China No. 2015CB251403 and Tianjin Natural Science Foundation No. 16JCYBJC20500.

\section{References}

[1] I. Dincer, Renewable energy and sustainable development: a crucial review, Renew. Sustain, Energy Rev. 4 (2) (2000) 157-175.

[2] Yang M, Patiño-Echeverri D, Yang F, et al. Industrial energy efficiency in China: achievements, challenges and opportunities, Energy Strategy Reviews, 2015, 6(1): $20-29$. 
401

402

403

404

405

406

407

408

409

410

411

[3] Johnson I, Choate W T, Davidson A. Waste Heat Recovery. Technology and Opportunities in US Industry, BCS, Inc., Laurel, MD (United States), 2008.

[4] S.S. Bertsch, E.A. Groll, Tspump for residential heating and cooling applications in northern US climates, Int. J.Refrig. 31(2008) 1282- 1292.

[5] P.K. Bansal, S. Jain, Cascade systems: past, present, and future, ASHRAE Trans. 113 (1) (2007) 245-252.

[6] Hae Won Jung, Hoon Kang, Won Ja Yoon, Yongchan Kim, Performance comparison between a single-stage and a cascade multi-functional heat pump for both air heating and hot water supply, Int. J. Refrig 36 (2013) 1431-1441

[7]Wang Bingming, Wu Huagen, Li Jianfeng, Xing Ziwen, Experimental investigation on the performance of $\mathrm{NH} 3 / \mathrm{CO} 2$ cascade refrigeration system with twin-screw compressor ,Int. J. Refrig 32 (2009) 1358-1365.

[8]J. Alberto Dopazo, Jose'Ferna'ndez-Seara, Experimental evaluation of a cascade refrigeration system prototype with $\mathrm{CO} 2$ and $\mathrm{NH} 3$ for freezing process applications, Int. J. Refrig 34 (2011) 257-267.

[9] Qu Minglu, Fan Yanan, Chen Jianbo, Li Tianrui, Li Zhao, Li He, Experimental study of a control strategy for a cascade air source heat pump water heater Applied Thermal Engineering 110 (2017) 835-843.

[10] Han saem Park, Dong Ho Kim, Min Soo Kim, Thermodynamic analysis of optimal intermediate temperatures in R134a\&R410A cascade refrigeration systems and its experimental verification, Applied Thermal Engineering 54 (2013) 319-327. 
[11] Dong Ho Kim, Han Saem Park, Min Soo Kim, Optimal temperature between high and low stage cycles for R134a/R410A cascade heat pump based water heater system, Thermal and Fluid Science 47 (2013) 172-179.

[12] Hansaem Park, Dong Ho Kim, Min Soo Kim ,Performance investigation of a cascade heat pump water heating system with a quasi-steady state analysis, Energy 63(2013) 283-294.

[13] H. Cho, C. Baek, C. Park, Y. Kim, Performance evaluation of a two-stage CO2 cycle with gas injection in the cooling mode operation, Int. J. Refrig. 32 (2009) 40-46.

[14] Xiaoyu Liu, Dingjiang Chen, An assessment of the energy-saving potential in China's petroleum refining industry from a technical perspective, Energy 59 (2013) 38-49.

[15] CHEN Chengmin, ZHANG Yufeng, DENG Na, MA Hongting, ZHANG Yansuo, MA Lijun , HU Xiaowei, Experimental Performance of Moderate and High Temperature Heat Pump Charged with Refrigerant Mixture BY-3, Trans. Tianjin Univ. 2011, 17: 386-390

[16] Danxing Z. Fluid and process thermodynamics, Textbook Publishing Center of Chemical Industry Press, 2005

[17] Morini M, Pavan C, Pinelli M, et al. Analysis of a scroll machine for micro ORC applications by means of a RE/CFD methodology, Applied Thermal Engineering, 2015, 80: 132-140. 
443 [18] Shengjun Z, Huaixin W, Tao G. Experimental investigation of moderately high 444 temperature water source heat pump with non-zeotropic refrigerant mixtures, Applied 445 Energy, 2010, 87(5): 1554-1561.

446 [19] Yongmei X. Theoretical and experimental study on new alternative refrigerants, 447 Ph. D. Thesis, Zhejiang University, China, 2004.

448 [20] Defibaugh D R, Morrison G. Interaction coefficients for 15 mixtures of 449 flammable and non-flammable components, International journal of refrigeration, $450 \quad 1995,18(8): 518-523$.

451 [21] Cao D S, Shi L. Refrigerant Manual[M]. Metallurgical Industry Press, Beijing, 452 China, 2003(in Chinese).

453 [22 ] State Administration of Quality Supervision, Inspection and 454 Quarantine,JJF1059.1-2012,National Metrology Technical Specifications of People's 455 Republic of China, Beijing: National Legal Measurement Management and 456 Measurement Technical Committee, 2012

457 [23] R.J. Moffat, Describing the uncertainties in experimental results, Int. J. Exp. 458 Therm. Fluid Sci. 1 (1998) 3-17. 